\title{
Climate science in 2009
}

\section{For climate science, the year 2009 brought significant discoveries and startling controversies.} Kurt Kleiner reports.

\section{WARMING GOES GLOBAL}

The year started out with some sobering, if not altogether surprising, news: overall, the Antarctic continent is warming. Although some of the Antarctic Peninsula had previously shown rapid warming, parts of the continent - especially near the South Pole - seemed to be unaccountably cooling.

In January, climatologist Eric Steig of the University of Washington in Seattle and colleagues reported (Nature 457, 459-462; 2009) that warming was widespread across the continent. Using satellite measurements combined with historical weather station data to interpolate Antarctic temperatures over the last 50 years, they found that the average temperature in West Antarctica had increased $0.1{ }^{\circ} \mathrm{C}$ per year. The previous apparent cooling resulted from the fact that prior to the use of satellites, data existed for only a relatively small number of weather stations.

Their findings were backed up by a study published in October. Writing in Geophysical Research Letters (36, L20704; 2009) Liz Thomas and colleagues from the British Antarctic Survey reported that an ice core taken in the southwestern Antarctic Peninsula showed warming of $2.7^{\circ} \mathrm{C}$ over the last 50 years.

These studies provided the necessary evidence to show that human-induced warming is happening globally. "We now see warming is taking place on all seven of the earth's continents in accord with what models predict as a response to greenhouse gases," Steig told the New York Times.

\section{CONFUSION OVER COOLING}

In March, a rather technical paper discussing climate periodicity was widely misinterpreted as suggesting that we are in a period of global cooling, and much energy was expended trying to set the record straight. Kyle Swanson and Anastasios A. Tsonis of the University of Wisconsin-Milwaukee reported in Geophysical Research Letters (36, L06711; 2009) that although temperatures rose overall during the twentieth century, distinct periods of warming and cooling of about 30 years each were superimposed on the warming trend.
The authors were investigating whether natural climate variability, including shortterm climatic events such as El Niño, could explain the shifts between these phases. The authors found that there are times when different types of natural variation in the climate synchronize, which shifts the climate to a new state. We might have entered such a phase in 2001-2002, in which case there could be a pause in warming before temperatures start rising again, said the authors.

Some critics took issue with their data sets and asked whether the pair were misinterpreting normal year-to-year variability, in which temperatures drop some years and increase in others even though the long-term trend is upward. "Regardless, it's important to note that we are not talking about global cooling, just a pause in warming," wrote Swanson on the Real Climate blog.

In September, the issue of cooling resurfaced following an address by Mojib Latif to the World Climate Conference in Geneva. Latif, a climatologist at the Leibniz Institute of Marine Sciences at Kiel University in Germany, was speaking of the need for greater accuracy in predicting climate change on a decade-by-decade scale. He noted that because of natural variability in the climate, it is theoretically possible that we could see "a decade, or maybe even two, when the temperature cools relative to the present level".

Some news accounts reported that Latif had predicted global cooling, and climate change deniers echoed the claims. Lost in the ensuing game of telephone was the fact that in both cases the researchers accept that overall warming is occurring and will continue in the long run.

In November the Met Office, the Natural Environment Research Council and the Royal Society in the UK issued a statement that the previous ten years were the hottest on record.

\section{SETTLING THE SCORE ON SEA LEVEL}

Throughout 2009, scientists made some headway on settling the score as to how much sea level could rise as temperature shoots up. In its 2007 report, the Intergovernmental Panel on Climate Change
(IPCC) estimated a maximum sea level rise of 59 centimetres by 2100 , but noted it was a low estimate because it excluded the contribution from dynamical processes such as the calving of icebergs, a phenomenon increasingly being observed around the edges of Greenland and Antarctica.

In March a Climate Change Congress in Copenhagen reported that sea levels could rise as much as one metre by 2100 . Part of the increase will come from 'thermal expansion' - oceans are apparently warming 50 per cent faster than was previously thought, and water expands as it heats up. The other part of the predicted rise comes from ice sheets melting more rapidly than expected in Greenland and Antarctica.

In September, Hamish Pritchard of the British Antarctic Survey and colleagues found (Nature 461, 971-975; 2009) that both ice sheets are melting much more rapidly than expected, thanks to a process known as 'dynamic thinning', in which warmer ocean water undercuts the edges of the sheets. Because dynamic thinning isn't well understood, it's possible that sea levels could rise even higher than one metre by 2100 .

But the case on sea level rise isn't completely closed. In July, Mark Siddall of Columbia University in New York and colleagues suggested (Nature Geosci. 2, 571; 2009) the IPCC estimates might have been about right. By simply calculating how sea level changed in the past relative to global temperature, they predicted that a temperature rise of $1.1^{\circ} \mathrm{C}$ by 2100 would raise sea levels only 7 centimetres, and an increase of $6.4^{\circ} \mathrm{C}$ would raise sea levels by 84 centimetres.

\section{MORE TALK ABOUT TARGETS}

Amidst continued discussions on targets - whether to stabilize atmospheric carbon dioxide concentrations at 450 or 350 parts per million, and whether peaking global emissions by 2015 or 2020 will be enough to avoid catastrophic warming - a group of scientists suggested it would be easier to concentrate on one nice round number.

The number? One trillion tonnes. That's the limit we should place on our cumulative carbon dioxide emissions if we 
are to have a reasonable chance of avoiding warming above $2{ }^{\circ} \mathrm{C}$, said Myles Allen of the University of Oxford and colleagues (Nature 348, 1163; 2009).

Given that we've already released more than half a trillion tonnes since the year 1750 , we have only another half-trillion tonnes to play around with. At current emissions rates, we'll reach that number in 40 years.

Politically, the trillion-tonne approach raises the risk that decision-makers will continue to put off action, reasoning that there's no hurry as long as we stop before the trillionth tonne. But Allen and co-authors say the cumulative approach emphasizes that there is a hard limit to emissions and that the more we delay, the more drastic the action we will have to take as the trillion-tonne mark looms nearer.

\section{CLIMATE SCIENCE ON DEMAND}

With emissions continuing to rise, governments looked to scientists for greater certainty on how climate change will play out at the local level. At the request of the UK government, in July 2009 scientists released a set of regional projections detailing how the nation - represented in 25-kilometre grid squares - will probably be affected by climate change.

Originally scheduled for release in November 2008, the projections were delayed owing to a last-minute call for an independent review to check the methodology. The review concluded the projections had serious limitations that needed to be made clear to users, and it led some to worry that the results "stretched the ability of current climate science".

The projections are part of a new effort called 'climate services', which will provide customized information on climate change to end users, including projections at ever decreasing scales. The projections will help specific regions prepare for likely changes such as increased drought, worse flooding or more frequent storms.

Despite the concerns raised by the ambitious UK projections, governments worldwide are keen to follow the UK's lead and to learn from its mistakes. In July, Germany opened the first national Climate Service Center in Hamburg. The United States also announced its intention to start a
National Climate Service. In September the World Meteorological Organization held a conference in Geneva and instituted a Global Framework for Climate Services to facilitate climate data sharing among countries.

\section{OVERSHOOTING AND ADAPTING}

With carbon emissions still rising, and political foot-dragging continuing, some scientists began to consider what the world will look like if we miss the target of limiting global temperature increase to $2{ }^{\circ} \mathrm{C}$ above pre-industrial levels.

Writing in April in Nature (458, 1102; 2009), Martin Parry of Imperial College London and colleagues warned that we should prepare to adapt to an overshoot of the $2{ }^{\circ} \mathrm{C}$ mark. Even if emissions peak in 2015 and decrease by three per cent per year, there's an even chance we'll exceed $2{ }^{\circ} \mathrm{C}$, they said. As a precaution, we should begin planning now to adapt to $4{ }^{\circ} \mathrm{C}$.

This message was reiterated at a conference in September in Oxford, by which stage scientists had done considerably more research on what $4{ }^{\circ} \mathrm{C}$ of warming would mean. Among other things, in a $4^{\circ} \mathrm{C}$ world

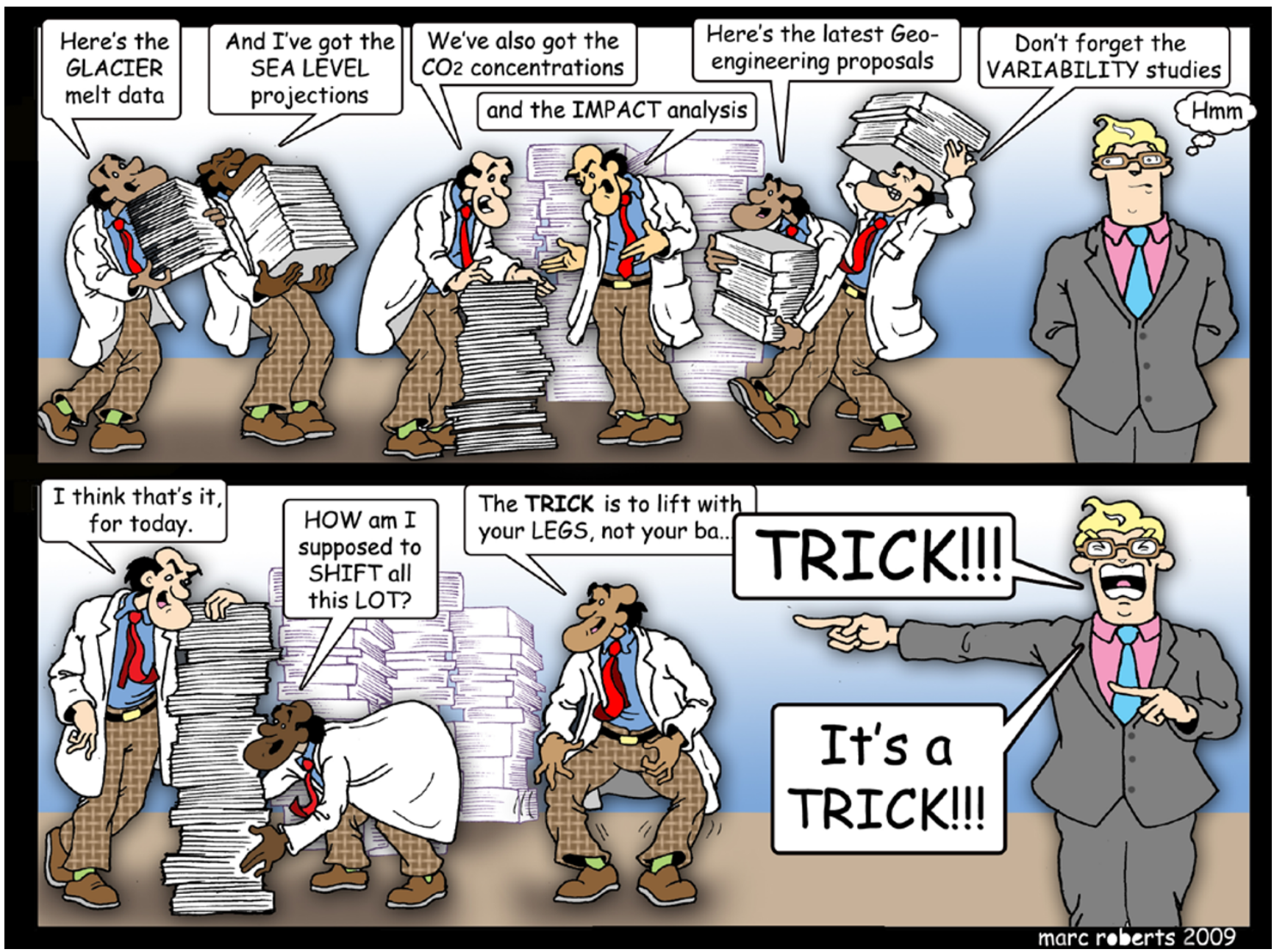


we could look forward to the destruction of US\$1 trillion worth of gross domestic product and displacement of 146 million people if sea levels rise a metre, as well as starvation, disease, fire and flooding.

Richard Betts, a researcher with the UK Met Office Hadley Centre in Exeter, told the conference that temperatures could reach $4{ }^{\circ} \mathrm{C}$ above pre-industrial levels by 2060 , in part because natural carbon sinks might lose their ability to absorb carbon from the atmosphere.

In November, a European consortium of 65 research centers concluded that to avoid overshooting $2{ }^{\circ} \mathrm{C}$, emissions would have to reach almost zero by 2100 , and we might need to start pulling carbon out of the atmosphere by 2050 .

\section{GEOENGINEERING GAINS GROUND}

During 2009, geoengineering took a few steps away from science fiction and towards reality. The idea that we ought to consider actively taking control of the climate has previously seemed fanciful, if not downright dangerous. But as emissions have continued to rise, the idea has become less marginalized.

In January, German and Indian scientists were temporarily blocked from dumping iron sulphate into the Southern Ocean. Their research into the effect of plankton blooms on ocean ecosystems was stalled owing to fears that it would provide insight into the feasibility of one geoengineering option (see Nature Rep. Clim. Change doi:10.1038/climate.2009.135; 2009). After finally getting approval from the German ministries, they were able to complete their experiment.

In August the UK Royal Society released a report that said geoengineering might soon be our only hope to reduce global warming if emissions aren't cut. In the United States, Congress held hearings on the topic and the National Academy of Sciences had a workshop to consider specific ideas. "At some point we will have to cross over and start sucking some of those gases out of the atmosphere," IPCC chairman Rajendra Pachauri told the London Times just prior to December's UN climate conference in Copenhagen.

While most still see geoengineering as a last and unappealing option, authors Steven Levitt and Stephen J. Dubner enthusiastically endorsed the concept in their book SuperFreakonomics, proposing it as a fast and cheap solution to the climate problem. Their suggestion that we could cool the planet simply by injecting aerosols into the atmosphere caused a ruckus. "The problem wasn't necessarily that you talked to the wrong experts or talked to too few of them. The problem was that you failed to do the most elementary thinking needed to see if what they were saying (or what you thought they were saying) ... made any sense," wrote Raymond T. Pierrehumbert, a climate scientist at the University of Chicago, in an open letter to Levitt.

\section{AEROSOL COOLING QUESTIONED}

Man-made aerosols have been thought to counter global warming by reflecting solar radiation directly and also by lengthening cloud lifetimes. But a review published in October (Nature 461, 607; 2009) concluded that they have different effects depending on the types of clouds and regions in which they form, and that in some cases they can actually shorten cloud life. Concluding that aerosol cooling is probably minimal, the authors called for more research.

\section{"Science doesn't work be-} cause we're all nice. Newton may have been an ass, but the theory of gravity still works." Gavin Schmidt

In a study also published in October (Science 326, 716; 2009), a team led by Drew Shindell of the NASA Goddard Institute for Space Studies in New York reported that the effect of aerosols on temperature depends on their interactions with other atmospheric gases. They found that over a 100-year period aerosol interactions increase the warming potential of methane by ten per cent, and when aerosol-cloud interactions are included, methane-induced warming increases by 20-40 per cent. The boost in warming from these interactions is partially offset by an increase in cooling from nitrogen oxides interacting with sulphate aerosols. The jury is still out on the overall influence of these tiny air-based particles.

\section{HOOPLA OVER HIMALAYAN GLACIERS}

In November, the Indian Ministry of the Environment and Forests released a controversial report from a retired glaciologist claiming that glaciers in the Himalayas are not melting in the face of global warming. The reports sparked angry responses from some scientists, outraged that it hadn't been peer-reviewed and was based on a sample of just 25 glaciers. In an interview with the Guardian, IPCC chairman Rajendra Pachauri called the findings unsubstantiated. The 2007 IPCC Report, after all, found that the 15,000 Himalayan glaciers were melting faster than any others in the world and might be completely gone by 2035 . Syed Iqbal Hasnain, a glaciologist with the Energy and Resources Institute in New Delhi, told the Hindu that the report used old data and that glaciers are in fact rapidly dwindling.

But Kenneth Hewitt, a glaciologist from Wilfrid Laurier University in Waterloo, Ontario, told the BBC that some Himalayan glaciers are, in fact, advancing. Changes in glaciers seem to vary depending on location and elevation, and there's not enough data to draw a general conclusion. "Climate change is happening here too, but with different consequences," Hewitt said.

\section{CLIMATEGATE CAUSES MORE CONFUSION}

Just ahead of the December UN negotiations on a climate deal, thousands of e-mails and documents were stolen from a server at the University of East Anglia Climatic Research Centre in the UK and posted on the internet. Predictably dubbed 'Climategate', the incident caused delight among climate change deniers and major embarrassment for some climate scientists - especially the centre's director, Phil Jones.

The e-mails show researchers speaking privately to one another, and it's not always pretty. They bad-mouth colleagues and critics ("The kindest interpretation is that he is a complete idiot ..., says one about another climate scientist). They discuss how to avoid releasing raw data to critics. They worry that certain journals are becoming too sympathetic to the other side.

Of most concern are e-mails that suggest researchers were massaging their results. In a 1999 e-mail, Jones says that he used a "trick" to "hide the decline" in one set of data in a chart. In another e-mail, Jones says he will keep two papers out of the IPCC report "even if we have to redefine what the peer-review literature is!" The "trick" seems to have referred to a statistical method to make up for defects in one set of suspect data, and the two papers were in fact discussed in the IPCC report.

What the e-mails do not show, however, is a grand conspiracy to concoct global warming. Instead, they show sincere researchers struggling to do good work in a highly politicized environment - and sometimes losing their tempers. "Science doesn't work because we're all nice," NASA climatologist Gavin Schmidt told the New York Times. "Newton may have been an ass, but the theory of gravity still works."

Published online: 17 December 2009

doi:10.1038/climate.2010.134

Kurt Kleiner is a freelance science writer based in Toronto. 